\title{
Placental thickness in third trimester and its correlation to gestational age and fetal weight in primigravida
}

\section{Badu M', Rajbhandari SBS'2, Regmi P2}

${ }^{1}$ Muna Badu, Lecturer; ${ }^{2}$ Shankar Bahadur Singh Rajbhandari, Consultant; ${ }^{2}$ Pashupati Regmi, Consultant; Department of Radiology, Kathmandu Medical College and Teaching Hospital, Sinamangal, Kathmandu, Nepal.

\begin{abstract}
Background: Gestational age and fetal weight estimation by ultrasound is the most effective and accurate method to date pregnancy. Ultrasound has been used to characterize placental position and morphologic changes. Placental thickness could be one additional parameter to assess gestational age and fetal weight.

Objectives: This study aims to investigate the relationship between placental thickness with gestational age and fetal weight in third trimester of pregnancy in primigravida.

Methodology: Prospective hospital based cross sectional study was conducted including 111 primigravida in third trimester with normal singleton pregnancies in Department of Radiology of Kathmandu Medical College Teaching Hospital from November 2018 to February 2019. Patients with known medical and obstetrical complications were excluded from the study. Placental thickness in millimeters was measured at the level of insertion of the umbilical cord. Pearson's correlation analysis was used for analyzing variables and $p$-value $<0.05$ was considered statistically significant. Results: Mean age of participants was $28.3 \pm 4.79$ years. Posterior location of the placenta was most common (35\%). Placental thickness correlated well with the gestational age and fetal weight. Pearson correlation coefficient was found to be 0.645 for placental thickness with gestational age and 0.598 for placental thickness with fetal weight. P-value was $<0.001$ in both, showing positive correlation of mentioned variables with placental thickness.

Conclusion: Placental thickness can be a new and reliable parameter for estimation of gestational age and fetal weight. It can be routinely used during antenatal checkup.
\end{abstract}

Key words: Fetal weight; Gestational age; Placental thickness.

DOI: https://doi.org/10.3126/jkmc.v8i3.29717

\section{INTRODUCTION}

7 stimation of gestational age is one of the important C parts of antenatal checkup. However, gestational age is often improperly estimated due to various reasons. Many women do not recall the first day of their last menstrual period, hence dating by ultrasound is often used in estimating the correct gestational age ${ }^{1}$. Ultrasound is the most effective and accurate method to date pregnancy. Placental evaluation by ultrasonography has been used to characterize placental position and morphologic changes, one

Address for correspondence

\section{Dr. Muna Badu}

Lecturer, Department of Radiology

Kathmandu Medical College and Teaching Hospital

Sinamangal, Kathmandu, Nepal

E-mail: muna.badusimkhada@gmail.com

ORCID: https://orcid.org/0000-0002-5673-5407 additional ultrasonographic parameter to assess the placenta can be the placental size ${ }^{2}$.

Low birth weight infants are prone to hypoxia and fetal distress, long-term handicap as well as fetal death. Therefore, an early detection of intrauterine growth retardation (IUGR) is extremely important for obstetric and neonatal care. Studies have shown that diminished placental size precedes fetal growth retardation ${ }^{3}$. Knowledge of normal placental size and estimation of accurate fetal age is always rewarding.

Several sonographically derived fetal parameters used to date pregnancy and fetal weight include fetal crown - rump length (CRL), biparietal diameter (BPD), head circumference $(\mathrm{HC})$, femur length $(\mathrm{FL})$, and abdominal circumference (AC). Placental thickness measured at the level of the umbilical cord insertion can be used as a new parameter to estimate gestational age of the fetus ${ }^{4}$. 
Evaluation of placental thickness in third trimester could help to determine normal development, function of placenta and can be a good predictor of fetal growth and birth weight ${ }^{5}$. This study was designed to observe the placental thickness in third trimester of pregnancy and see its correlation with gestational age and fetal weight in primigravida visiting Kathmandu Medical College and Teaching Hospital.

\section{METHODOLOGY}

Prospective hospital based cross sectional study was conducted in 111 primigravida with gestational age from 28 weeks to 40 weeks in the Department of Radiology of Kathmandu Medical College Teaching Hospital. Normal singleton pregnancies referred from Department of Obstetrics and Gynaecology for routine antenatal ultrasound during November 2018 to February 2019 were included consecutively. Subjects with known medical and obstetrical complications were excluded from the study. Ethical clearance was obtained from the Institutional Review Committee of Kathmandu Medical College Teaching Hospital. Informed consent was obtained from all the participants.

Gray Scale real time examinations were performed using Toshiba Xario and Aplio 400 with $3.5 \mathrm{MHz}$ convex array transducer. Placental thickness in millimeters was measured at the level of insertion of the umbilical cord.

Statistical analysis was done using Statistical Package for the Social Sciences version 20; graphs and tables were generated using Microsoft Word and Excel. Pearson's correlation analysis was used for analyzing variables. P-value $<0.05$ was considered statistically significant.

\section{RESULTS}

Among 111 primigravida included in the study, the age ranged from 19 to 40 years with mean being $28.3 \pm 4.79$ years. The placenta was found in the posterior location in 39 cases (35\%), anterior location in 35 cases (31\%), fundal in 14 cases $(21 \%)$ and lateral in 23 cases (13\%) as shown in figure 1.

The minimal placental thickness was $24 \mathrm{~mm}$ and maximum was $61 \mathrm{~mm}$. There was gradual increase in placental thickness from 28 weeks to 39 weeks. However, the size of placenta was relatively smaller in the $40^{\text {th }}$ week of gestation. The distribution of placental thickness is shown in table 1 and gradual increase in placental thickness up to 39 weeks has been demonstrated in figure 2. Placental thickness correlated with fetal weight. There was increase in placental thickness with increase in fetal weight as shown in figure 3.

There was positive correlation between placental thickness and gestational age. Pearson correlation coefficient ' $r$ ' was 0.645 and $p$-value was $<0.001$. Similarly, there was significant positive correlation between placental thickness and fetal weight. Pearson correlation coefficient ' $r$ ' was 0.598 and $p$-value was $<0.001$.

\section{Table 1: Distribution of placental thickness according to gestational age}

\begin{tabular}{|ccc|}
\hline Gestational age & $\begin{array}{c}\text { Frequency } \\
\text { (Percentage) }\end{array}$ & $\begin{array}{c}\text { Mean placental } \\
\text { thickness in } \\
\text { millimeters }\end{array}$ \\
\hline 28 weeks & $7(6.3)$ & 25.01 \\
\hline 29 weeks & $4(3.6)$ & 27.08 \\
\hline 30 weeks & $8(7.2)$ & 28.88 \\
\hline 31 weeks & $0(0)$ & 0 \\
\hline 32 weeks & $14(12.6)$ & 29.62 \\
\hline 33 weeks & $4(3.6)$ & 32.87 \\
\hline 34 weeks & $19(17.1)$ & 34.76 \\
\hline 35 weeks & $6(5.4)$ & 37.95 \\
\hline 36 weeks & $13(11.7)$ & 39.95 \\
\hline 37 weeks & $16(14.4)$ & 40.74 \\
\hline 38 weeks & $13(11.7)$ & 42.37 \\
\hline 39 weeks & $3(2.7)$ & 42.63 \\
\hline 40 weeks & $4(3.6)$ & 42.28 \\
\hline
\end{tabular}

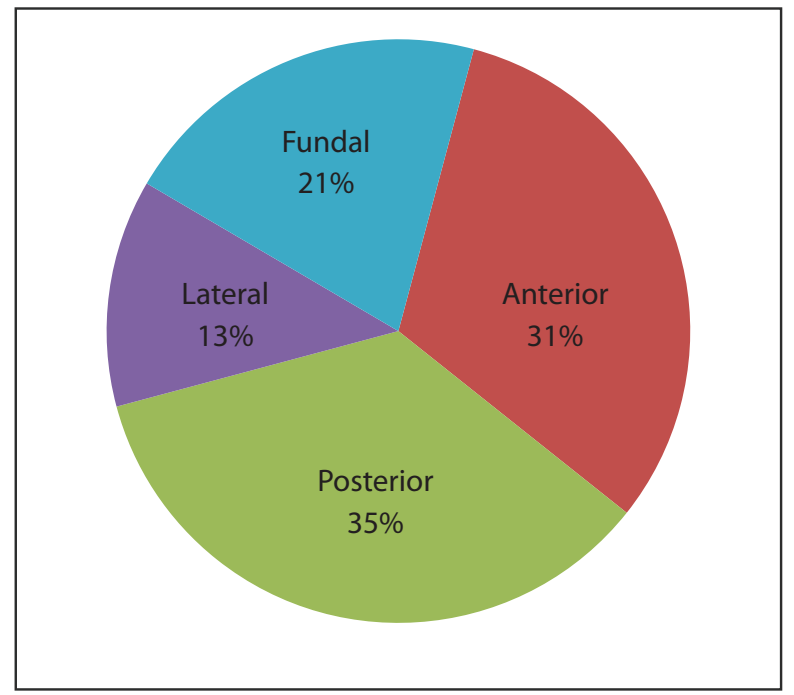

Figure 1: Placental position 


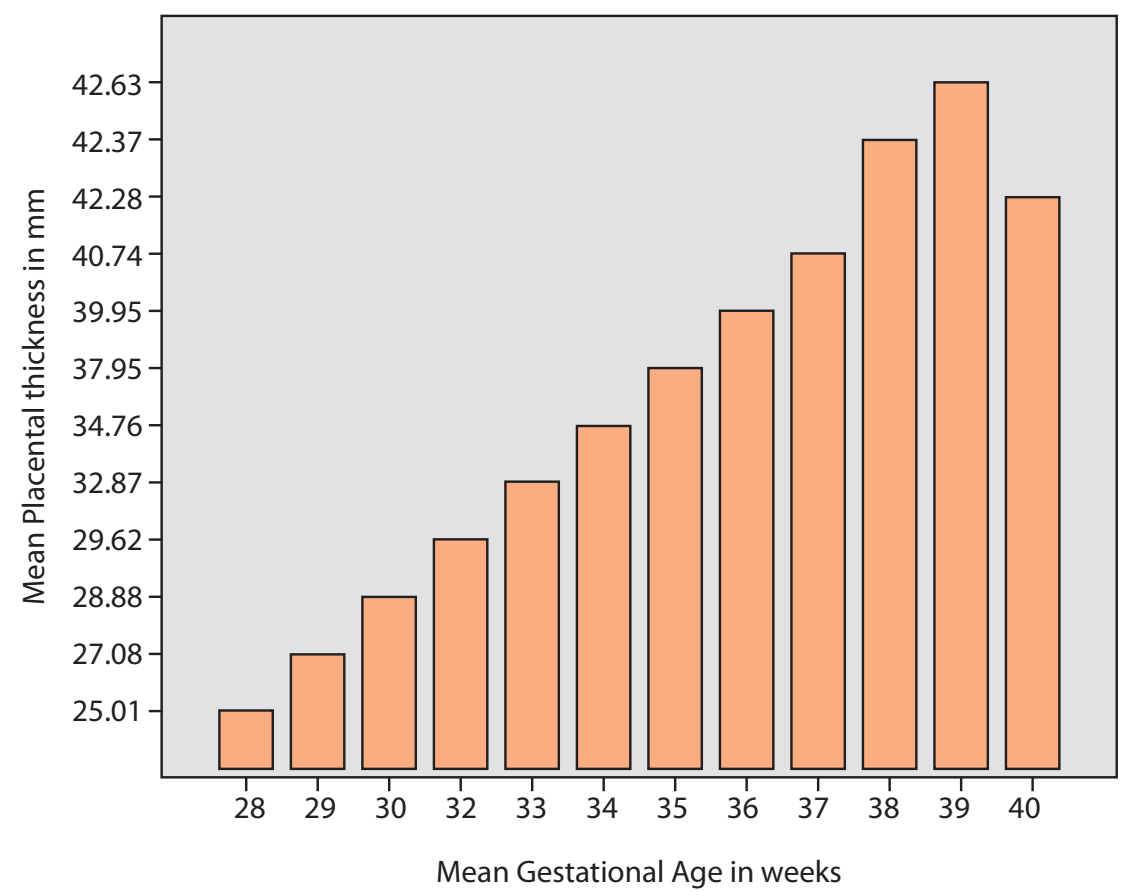

Figure 2: Gestational age against placental thickness

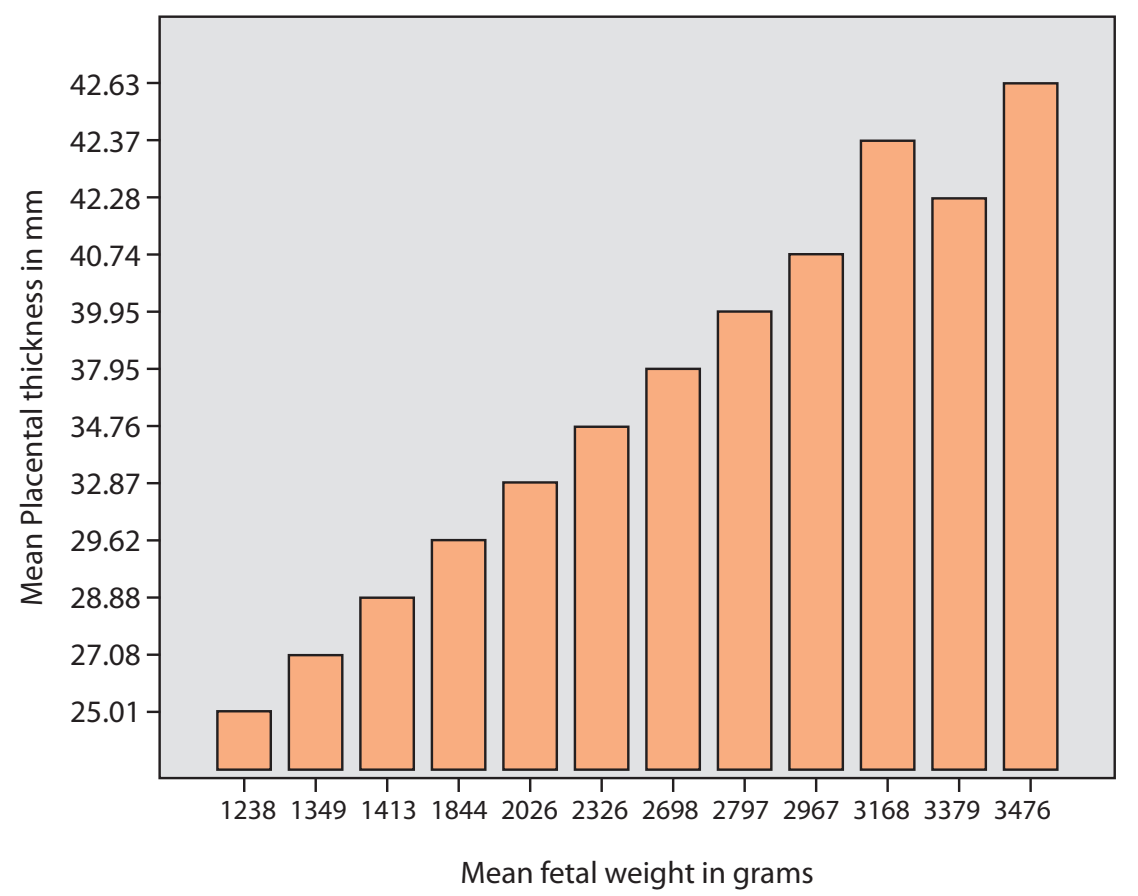

Figure 3: Fetal weight against placental thickness 


\section{DISCUSSION}

Determination of gestational age and estimated fetal weight are important because it provides valuable information regarding the condition of the fetus and directly affects the management of the pregnancy.

Fadl et $\mathrm{al}^{6}$ stated that placenta of greater than $40 \mathrm{~mm}$ should be considered thickened. A thickened placenta has been described in association with TORCH infections, gestational diabetes, and fetal hydrops. However, in our study the maximum thickness of placenta was $61 \mathrm{~mm}$ without any associated pathologies.

The present study was conducted to assess the relationship between placental thickness with gestational age and fetal weight. We found that placental thickness increases steadily with gestational age in a linear fashion and also matches with fetal weight.

The results of our study are consistent with the findings of previous studies. In a cross sectional study by Karthikeyan et al. ${ }^{7}$, placental thickness correlated with gestational age and fetal growth. Nyberg and Finberg ${ }^{8}$ also reported that placental thickness parallels gestational age. Nagwani et al. ${ }^{9}$ conducted an ultrasonographic study of placental maturity and its correlation with gestational age and maternal parameters in 100 patients in India. They found placental thickness roughly equivalent to gestational age. Baghel et al. ${ }^{10}$ reported that placental thickness matches with gestational age. Habib et al. ${ }^{11}$ concluded that placental thickness was a predictor of low birth weight infants. Similarly, Abu et al. ${ }^{12}$ found a strong positive correlation between placental thickness and estimated fetal weight and found that placental

\section{REFERENCES}

1. Kaushal L, Patil A, Kocherla K. Evaluation of placental thickness as a sonological indicator for estimation of gestational age of foetus in normal singleton pregnancy. Int J Res Med Sci. 2015;3:1213-8. [FullText | DOI]

2. Tongsong T, Boonyanurak P. Placental thickness in the first half of pregnancy. J Clin Ultrasound. 2004;32:231-4. [PubMed | FullText | DOI]

3. Mathai BM, Singla SC, Nittala PP, et al. Placental thickness: Its correlation with ultrasonographic gestational age in normal and intrauterine growthretarded pregnancies in the late second and third trimester. J Obstet Gynaecol India. 2013;63:230-3. [PubMed | FullText | DOI] thickness can be used as a fairly accurate indicator of fetal weight which was consistent with our findings. There was a slight decrease in placental size noted in the 40th week. This could be due to enrollment of only few participants in that time period. Similar result was shown in a study done by Nagwani et al ${ }^{9}$.

Placental thickness can be a useful marker to predict gestational age and fetal weight. It can also be used where other parameters like head circumference and biparietal diameter in hydrocephalus are not reliable.

This was a cross sectional, single centre study with small sample size. The subjects were examined only one time. Placental thickness was measured at the site of umbilical cord insertion only. Large sample size with longitudinal study and volume measurement of placenta would have been more accurate. Larger studies and scanning at regular intervals starting from beginning of second trimester to find out the relationship between placental thickness with gestational age and fetal weight is recommended and expected in the future.

\section{CONCLUSION}

Placental thickness correlated well with gestational age and fetal weight in our study. Therefore, placental thickness can be an additional parameter to estimate gestational age and fetal weight with advancing gestational age.

\section{ACKNOWLEDGEMENTS}

The authors would like to thank all the staffs of Department of Radiology of KMCTH.

4. Mital P, Hooja N, Mehndiratta K, et al. Placental thickness: a sonographic parameter for estimating gestational age of the fetus. Indian J Radiol Imaging. 2002;12:553-4. [FullText]

5. Afrakhteh M, Moeini A, Taheri MS, et al. Correlation between placental thickness in the second and third trimester and fetal weight.Rev Bras Ginecol Obstet. 2013;35:317-22. [PubMed | Full Text | DOI]

6. Fadl S, Moshiri M, Fligner CL, et al. Placental Imaging: Normal Appearance With Review of Pathologic Findings. Radiographics. 2017;37(3):979-98. [PubMed | FullText | DOI]

7. Karthikeyan T, Subramaniam RK, Johnson W, et al.Placental thickness and its correlation to gestational age and foetal growth parameters- a 
cross sectional ultrasonographic study. J Clin Diagn Res. 2012;6:1732-5. [PubMed | FullText | DOI]

8. Nyberg DA, Finberg HJ. The placenta, placental membranes and umbilical cord. In: Newburgh DA, Mahony BS, Pretorius DH, editors. Diagnostic ultrasound of foetal anomalies. St.Louis: Mosby year book publishers; 1990.p.623-75.

9. Nagwani $M$, Sharma $P K$, Singh $U$, et al. Ultrasonographic measurement of placental thickness and its correlation with gestational age - a cross-sectional ultrasonographic study. International Journal of Advanced Research. 2014;2:354- 60. [FullText]
10. Baghel P, Bahel V, Paramhans R, et al. Correlation of placental thickness estimated by ultrasonography with gestational age and fetal outcome. Indian Journal of Neonatal Medicine and Research. 2015;3:19-24. [FullText]

11. Habib FA. Prediction of low birth weight infants from ultrasound measurement of placental diameter and thickness. Annals of south Saudi Medicine. 2002;22(5-6):312-4. [FullText | DOI]

12. Abu PO, Ohagwu CC, Eze JC, et al. Correlation between placental thickness and estimated fetal weight in Nigerian women. Ibnosina J Med Biomed Sci. 2009;1(3):80-5. [FullText]. 